\title{
Beta-blocker efficacy across different cardiovascular indications: an umbrella review and meta-analytic assessment
}

Oliver J. Ziff ${ }^{1,2}$, Monica Samra ${ }^{2}$, James P. Howard ${ }^{3}$, Daniel I. Bromage ${ }^{2,4}$, Frank Ruschitzka ${ }^{5}$, Darrel P. Francis ${ }^{3}$ and Dipak Kotecha ${ }^{1,6,7^{*}}$

\begin{abstract}
Background: Beta-blockers are widely used for many cardiovascular conditions; however, their efficacy in contemporary clinical practice remains uncertain.

Methods: We performed a prospectively designed, umbrella review of meta-analyses of randomised controlled trials (RCTs) investigating the evidence of beta-blockers in the contemporary management of coronary artery disease (CAD), heart failure (HF), patients undergoing surgery or hypertension (registration: PROSPERO CRD42016038375). We searched MEDLINE, EMBASE and the Cochrane Library from inception until December 2018. Outcomes were analysed as beta-blockers versus control for all-cause mortality, myocardial infarction (MI), incident HF or stroke. Two independent investigators abstracted the data, assessed the quality of the evidence and rated the certainty of evidence.

Results: We identified 98 meta-analyses, including 284 unique RCTs and 1,617,523 patient-years of follow-up. In CAD, 12 meta-analyses (93 RCTs, 103,481 patients) showed that beta-blockers reduced mortality in analyses before routine reperfusion, but there was a lack of benefit in contemporary studies where $\geq 50 \%$ of patients received thrombolytics or intervention. Beta-blockers reduced incident MI at the expense of increased HF. In HF with reduced ejection fraction, 34 meta-analyses (66 RCTs, 35,383 patients) demonstrated a reduction in mortality and HF hospitalisation with beta-blockers in sinus rhythm, but not in atrial fibrillation. In patients undergoing surgery, 23 meta-analyses (89 RCTs, 19,211 patients) showed no effect of beta-blockers on mortality for cardiac surgery, but increased mortality in non-cardiac surgery. In non-cardiac surgery, beta-blockers reduced MI after surgery but increased the risk of stroke. In hypertension, 27 meta-analyses (36 RCTs, 260,549 patients) identified no benefit versus placebo, but beta-blockers were inferior to other agents for preventing mortality and stroke.
\end{abstract}

Conclusions: Beta-blockers substantially reduce mortality in HF patients in sinus rhythm, but for other conditions, clinicians need to weigh up both benefit and potential risk.

Keywords: Systematic review, Coronary artery disease, Heart failure, Hypertension, Perioperative, Meta-analysis, Mortality, Myocardial infarction, Stroke

\footnotetext{
* Correspondence: d.kotecha@bham.ac.uk

'University of Birmingham Institute of Cardiovascular Sciences, Medical School, Birmingham B15 2TT, UK

${ }^{6}$ Monash Centre of Cardiovascular Research \& Education in Therapeutics, Monash University, Melbourne, Victoria 3004, Australia

Full list of author information is available at the end of the article
}

(c) The Author(s). 2020 Open Access This article is licensed under a Creative Commons Attribution 4.0 International License, which permits use, sharing, adaptation, distribution and reproduction in any medium or format, as long as you give appropriate credit to the original author(s) and the source, provide a link to the Creative Commons licence, and indicate if changes were made. The images or other third party material in this article are included in the article's Creative Commons licence, unless indicated otherwise in a credit line to the material. If material is not included in the article's Creative Commons licence and your intended use is not permitted by statutory regulation or exceeds the permitted use, you will need to obtain permission directly from the copyright holder. To view a copy of this licence, visit http://creativecommons.org/licenses/by/4.0/ The Creative Commons Public Domain Dedication waiver (http://creativecommons.org/publicdomain/zero/1.0/) applies to the data made available in this article, unless otherwise stated in a credit line to the data. 


\section{Introduction}

Beta-blockers are an established part of the routine management for many cardiovascular conditions and are widely used by physicians across the spectrum of healthcare. They act via multiple pathways, limiting the effects of catecholamine excess, affecting inotropy and chronotropy, providing anti-arrhythmic and anti-ischaemic effects and inhibiting renin release. However, this diversity of action carries the possibility of varying net effects on individual outcomes, depending on patient characteristics and disease substrate. Beta-blockers are well tolerated even in patients with advanced conditions such as heart failure with reduced ejection fraction (HFrEF), as confirmed in double-blind randomised controlled trials (RCTs) [1]. Although side effects such as dizziness, lethargy and cold extremities are commonly reported in clinical practice, similar rates are seen with placebo [2]. Beta-blockers can cause bradycardia, atrioventricular block and symptomatic hypotension, especially in patients with sinus and/or atrioventricular node dysfunction [3], and are contraindicated in severe asthma because of the risk of life-threatening bronchospasm [4].

The balance of risk versus benefit remains unclear in many cardiovascular conditions. For example, in acute coronary syndromes (ACS) and patients with coronary artery disease (CAD), many RCTs predate reperfusion strategies and contemporary medical treatment $[5,6]$. There have also been questions about the efficacy of beta-blockers in HFrEF patients with concomitant atrial fibrillation [7] and safety concerns for patients undergoing non-cardiac surgery and in hypertension [8-10]. These uncertainties have contributed to suboptimal uptake in patient groups where beta-blockers are known to reduce mortality and morbidity. Indeed, patients at greatest risk of death seem least likely to receive evidence-based therapy $[11,12]$. The aim of our study was to review all available evidence for beta-blocker therapy across these different cardiovascular indications, providing clear assistance for clinicians and to inform future guidelines. For each condition, we used an evidencebased hierarchy that first identified the availability of individual patient data (IPD) meta-analyses, and if not, whether there were aggregate data meta-analyses with unbiased data to better understand the balance of efficacy and safety of beta-blockers.

\section{Methods}

Due to the comprehensive assessment, the main text focuses on the most robust findings with clinical impact; all additional data are available in the Online Data Supplement. The project was prospectively registered with the PROSPERO database of systematic reviews (CRD42016038375, [13]) and conducted according to the Preferred Reporting Items for Systematic reviews and Meta-Analyses (PRISMA) guidelines [14]. A systematic review of MEDLINE, EMBASE, the Cochrane
Library and other sources was performed (1960 to December 2018). Additional details on methodology are presented in the Supplemental Methods.

\section{Study selection}

We included meta-analyses of RCTs that looked at the clinical effects of beta-blockers on adults in four cardiovascular indications: $\mathrm{CAD}$, heart failure, perioperative risk reduction and hypertension. Definitions of cardiovascular conditions and outcomes used by each individual metaanalysis were accepted and are reported in Supplemental Table 1. Administration of beta-blockers was via any route versus control (placebo or no treatment). In the hypertension population, we also included meta-analyses comparing beta-blockers with another active drug. Supplemental Tables 1 and 2 provide details and references for all included and excluded meta-analyses, respectively.

\section{Data extraction}

The predefined primary outcome was all-cause mortality. Secondary outcomes were cardiovascular mortality, incident myocardial infarction (MI), heart failure and stroke, as relevant to the cardiovascular indication.

\section{Quality assessment}

We employed an evidence-based hierarchy to determine the quality of data. The first stage was the type of metaanalysis, with IPD meta-analyses ranking first, and then aggregate tabular data meta-analyses (herein simply referred to as meta-analyses). The second stage involved careful exploration of study quality and potential bias using AMSTAR (A Measurement Tool to Assess Multiple Systematic Reviews) and ROBIS (Risk of Bias in Systematic Reviews, Supplemental Table 3). The certainty of evidence was evaluated using the GRADE (Grading of Recommendations Assessment, Development and Evaluation) approach and was classified as high, moderate, low or very low (Supplemental Table 4 and using the GRADEproGDT software at gdt.gradepro.org/app/) [15].

\section{Data synthesis and analysis}

The outcome data from each meta-analysis was summarised as a risk ratio (RR) using an intention-to-treat approach and graphed in a forest plot. RR and associated 95\% confidence intervals $(\mathrm{CI})$ were calculated using the published outcome data. These effect estimates were not pooled, as many of the meta-analyses within the same indication included the same trials; instead, we display the range of confidence intervals and highlight the highest quality/lowest bias estimates of beta-blockers versus control. Heterogeneity across trials is displayed as the $I^{2}$ statistic. A two-tailed $p$ value of 0.05 was considered statistically significant. Analyses were performed on Stata version 14.1 (StataCorp LP, Texas). 


\section{Results}

We identified 98 meta-analyses suitable for quantitative synthesis. These included 284 unique RCTs, with 418, 624 unique patients on beta-blocker therapy or control, and 1,617,523 patient-years of follow-up (Supplemental Figure 1). The risk of bias was variable in the metaanalyses, but generally low (Supplemental Table 3 and Supplemental Figure 2). There were notable exceptions, including potential bias in data collection and study selection in heart failure, and moderate overall risk of bias in hypertension studies. Quality and risk of bias corresponded to the robustness of the study design, with IPD and prospectively registered meta-analyses demonstrating the highest quality and lowest risk of bias.

\section{Coronary artery disease}

There were no IPD studies and 12 other meta-analyses meeting inclusion criteria, comprising 93 individual RCTs, 103,481 participants, mean follow-up of 7.8 months (range: in-hospital to 6 years) and a total of 55,536 patient-years of follow-up. The RCTs were predominantly historical, being performed before the routine use of reperfusion strategies; only 8 trials included patients where $\geq 50 \%$ of patients received thrombolytics or intervention. A summary of the most contemporary data is presented in Fig. 1 and detailed analysis in Supplemental Figure 3.

\section{All-cause mortality}

In studies before routine reperfusion, beta-blockers reduced mortality compared to control in acute metaanalyses (within $48 \mathrm{~h}$ of $\mathrm{MI}, \mathrm{RR}$ range 0.83 to 0.98 ) and non-acute meta-analyses (after $48 \mathrm{~h}, \mathrm{RR}$ range 0.38 to 0.96 ). Where sub-group analyses were performed to assess trials with routine reperfusion (where $\geq 50 \%$ of patients received thrombolytics or intervention), beta-blockers did not reduce mortality either in the acute setting (12 RCTs, 48,806 participants; RR 0.98 , 95\% CI $0.92-1.04$ ) or in non-acute

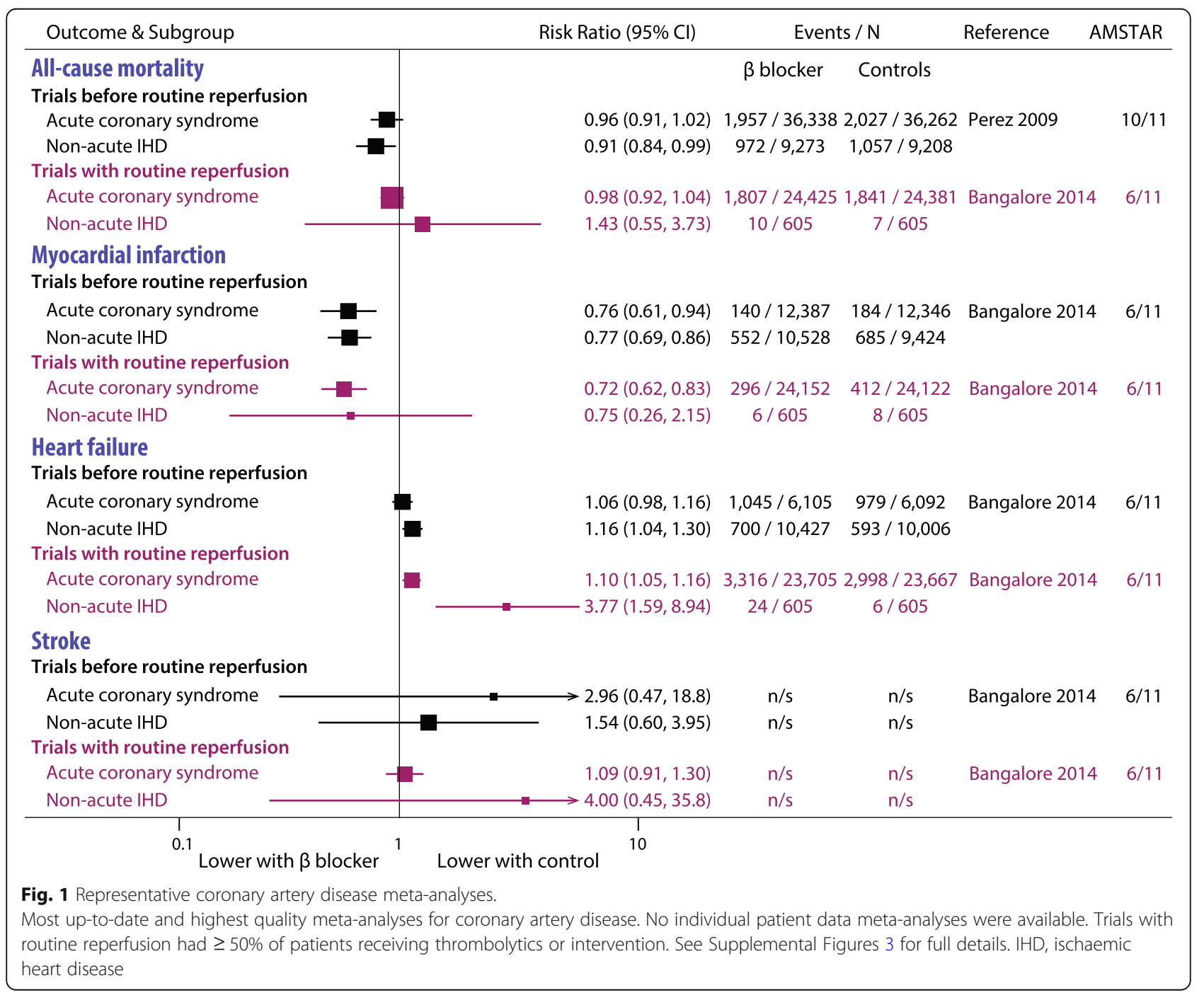


MI (2 RCTs, 1210 participants; RR 1.43, 95\% CI $0.55-3.73)$.

\section{Incident $\mathrm{MI}$}

In trials before routine reperfusion, beta-blockers reduced MI in both the acute setting (48 RCTs with 24, 773 participants; RR 0.76, 95\% CI 0.61-0.94) and nonacute setting (18 RCTs with 20,637; RR 0.77, 95\% CI 0.69-0.86). Beta-blockers reduced incident MI in studies with routine reperfusion only in the acute setting (12 RCTs with 48,274 participants, RR 0.72, 95\% CI $0.62-$ 0.83 ; non-acute setting 2 RCTs with 1210 participants, RR $0.75,0.26-2.15)$.

\section{Heart failure}

In the acute setting, incident heart failure tended to be more common with beta-blockers than control, but this was only significant in trials with routine reperfusion (9 RCTs with 47,272 participants; RR 1.10, 95\% CI 1.05-1.16). Beta-blockers increased incident heart failure in the non-acute setting in trials both before routine reperfusion (17 RCTs with 20,433 participants; RR 1.16, 95\% CI 1.04-1.30) and with routine reperfusion (2 RCTs with 1210 participants; RR 3.77, 95\% CI 1.59-8.94).

\section{Stroke}

In both the acute and non-acute setting, beta-blockers had no effect on incident stroke either before routine reperfusion (acute RR 2.96, 95\% CI 0.47-18.81; non-acute RR 1.54, 95\% CI 0.60-3.95), or with routine reperfusion (acute RR 1.09, 95\% CI 0.91-1.30; non-acute RR 4.00, 95\% CI 0.45-35.79).

\section{Heart failure}

Four IPD studies and 31 other meta-analyses met inclusion criteria, comprising 66 individual RCTs, 35,383 participants, mean follow-up of 12.3 months (range 3 to 32 months) and a total of 534,461 patient-years of followup. The RCTs were predominantly in patients with HFrEF; only 3 trials were designed to include patients with left ventricular ejection fraction (LVEF) $>40 \%$. A summary of the highest quality data is presented in Fig. 2 and detailed analysis in Supplemental Figure 4.

\section{All-cause mortality}

IPD meta-analysis of 11 double-blind, placebocontrolled RCTs demonstrated that beta-blockers significantly reduced mortality in patients with sinus rhythm (13,833 patients; RR $0.76,95 \%$ CI $0.70-0.82)$, regardless of age, gender or achieved heart rate. However, there

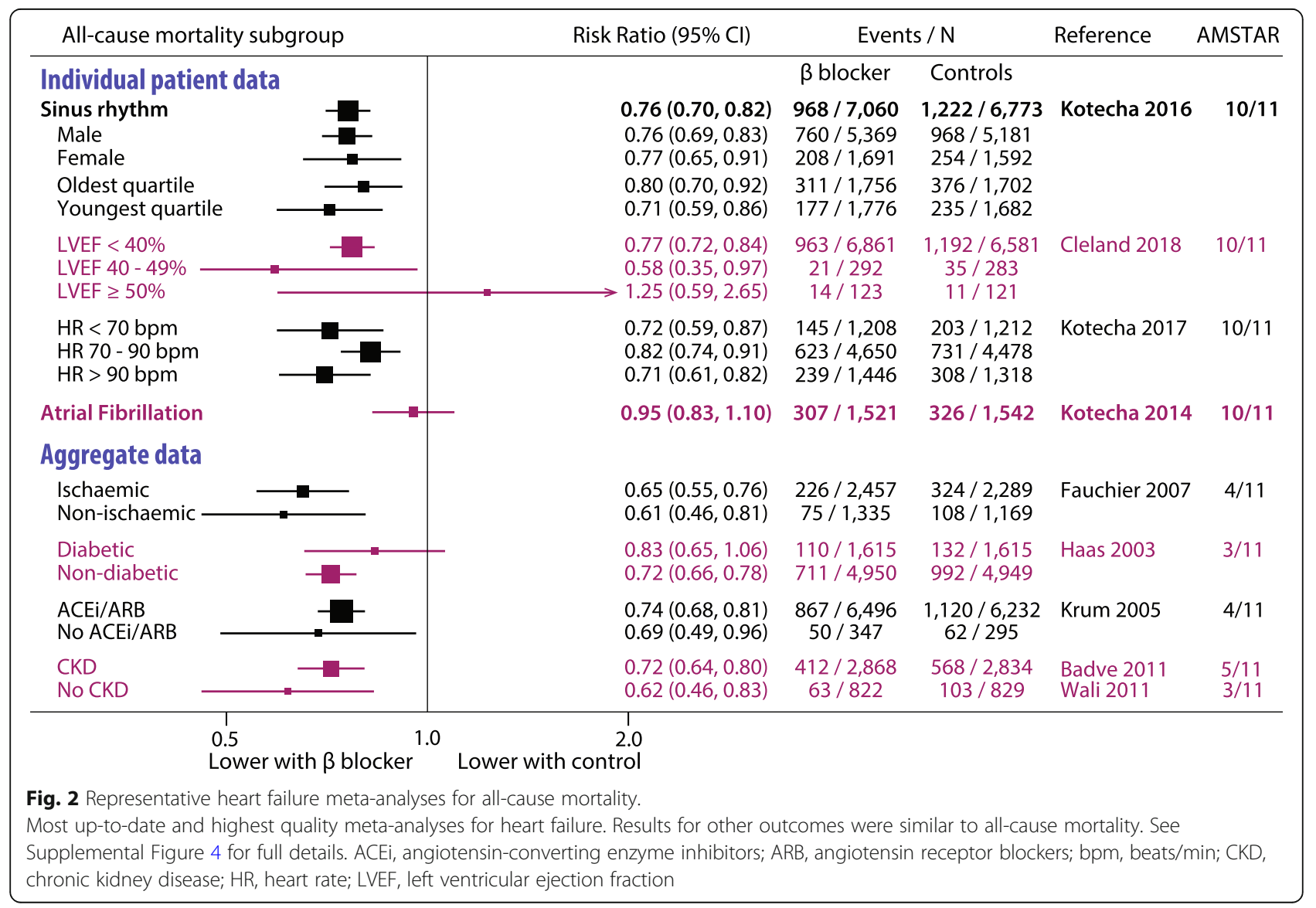


was no reduction in mortality in the subgroups with atrial fibrillation (3064 patients; RR 0.95, 0.83-1.10; $p_{\text {in- }}$ teraction 0.002 for rhythm on baseline electrocardiogram) [7], or the small subgroup with LVEF $\geq 50 \%$ [16]. In non-IPD meta-analyses, beta-blockers were associated with reduced mortality compared to control, but findings were non-significant in subgroups with atrial fibrillation, LVEF $>40 \%$ and black patients, and inconsistent in patients with diabetes.

\section{Cardiovascular mortality, heart failure hospitalisation and stroke}

In both IPD and other meta-analyses, patients in (or predominantly in) HFrEF and sinus rhythm had substantial reduction in cardiovascular mortality and heart failure hospitalisation with beta-blockers compared to control. Beta-blockers had no effect on non-fatal stroke compared with placebo $(16,644$ patients) in patients in HFrEF, irrespective of if they were in sinus rhythm (HR 1.02, 95\% CI 0.78-1.32) or atrial fibrillation (HR 1.04, 95\% CI 0.66-1.63).

\section{Perioperative risk reduction}

There were no IPD studies. Twenty-three other metaanalyses with 89 individual RCTs were included, with 19,211 participants followed-up for a mean of 1 month (range $24 \mathrm{~h}$ to 2 years; 1925 patient-years of follow-up). A summary of representative data is presented in Fig. 3 and detailed analysis in Supplemental Figure 5.

\section{All-cause mortality}

In non-cardiac surgery, we saw a clear distinction in treatment effect according to the risk of bias. In small meta-analyses with high risk (that included the DECREASE studies), there were reductions in mortality with beta-blockers. Conversely, all large meta-analyses with low risk of bias in non-cardiac surgery suggested that beta-blockers increased mortality compared to control, ranging from RR 1.03 to 1.31. Meta-analyses in patients undergoing cardiac surgery showed no significant effect of beta-blocker therapy.

\section{Incident MI and stroke}

Beta-blockers were consistently associated with a reduced risk of incident MI after non-cardiac surgery (point estimate RR range 0.08 to 0.92 ), but an increased risk of stroke (RR range 1.33 to 7.72). None of the metaanalyses in cardiac surgery identified any significant difference with beta-blockers or control for either incident MI or stroke.

\section{Hypertension}

There were no IPD studies and 28 other metaanalyses, with 36 individual RCTs and 260,549 participants followed up for a mean of 3.7 years (range 1 to 10 years; $1,025,601$ patient-years of follow-up). Summary findings are displayed in Fig. 4 and full analysis in Supplemental Figure 6.

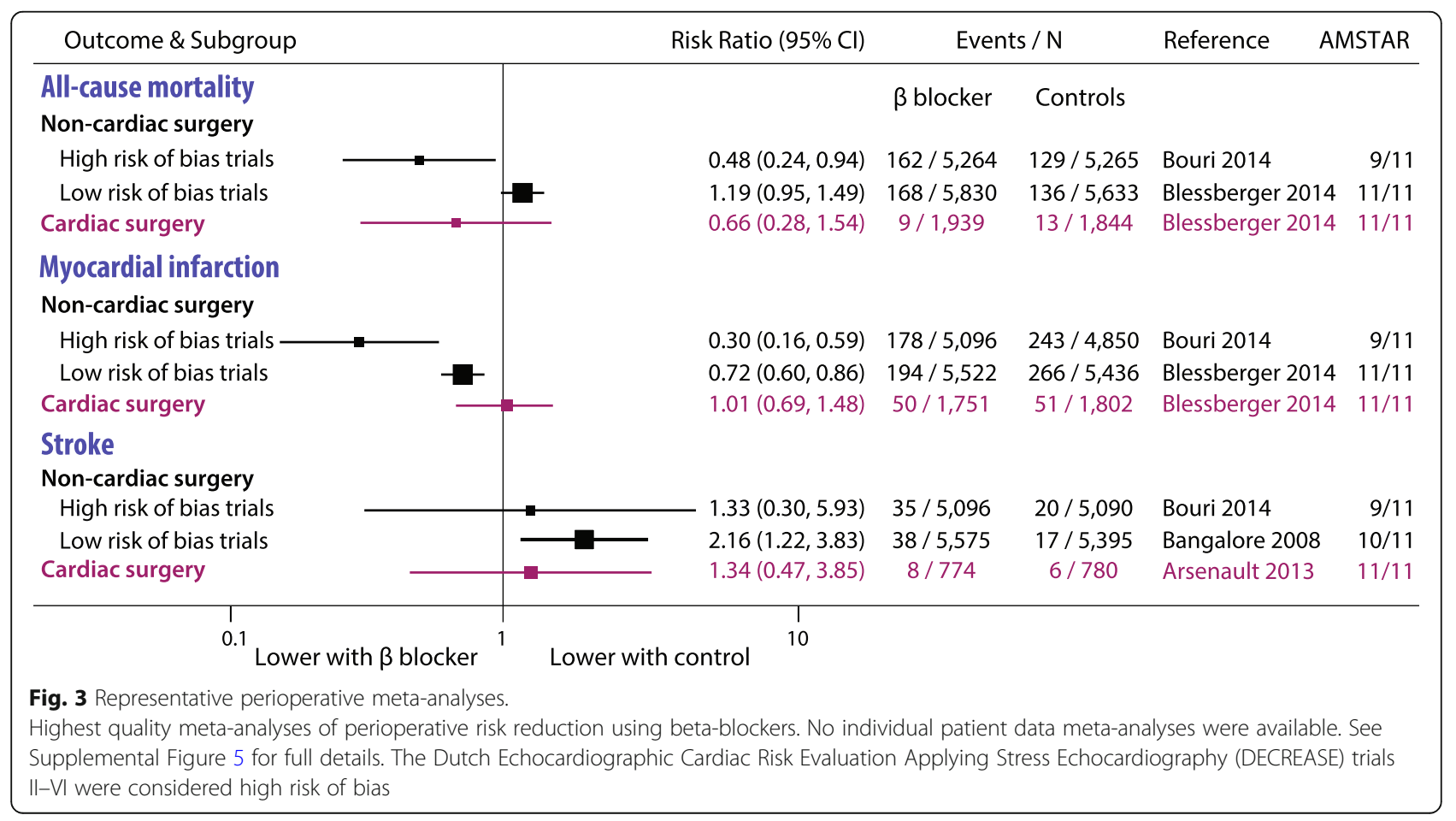




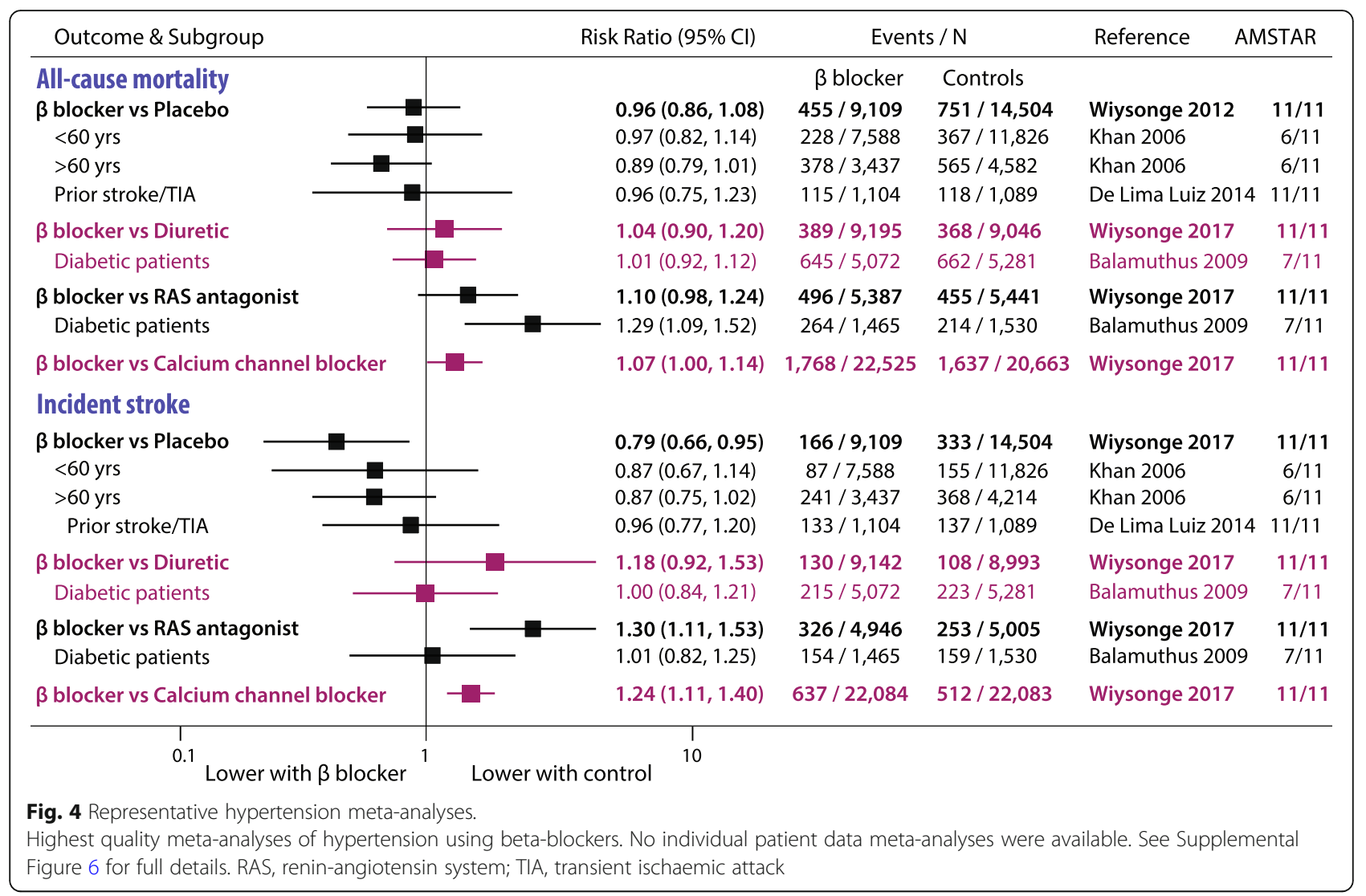

\section{All-cause mortality}

Mortality was not significantly different in any of 18 meta-analyses comparing beta-blockers with either placebo or diuretics. Compared to renin-angiotensin system (RAS) antagonists, all 5 meta-analyses demonstrated a trend to increased mortality with betablockers, ranging from RR 1.08 to 1.29 , with diabetic patients showing a significant increase. Compared to $\mathrm{CCB}$, all 3 meta-analyses demonstrated significantly increased mortality with beta-blockers (RR range 1.07 to 1.11$)$.

\section{Incident MI and stroke}

Across meta-analyses, there were no consistent differences in incident MI comparing beta-blockers with either placebo or other therapy. Incident stroke rates were significantly increased with beta-blockers versus either RAS antagonists or CCB (representative RR 1.30 and 1.24 , respectively), although not in diabetic patients.

\section{Sensitivity analysis}

There were no consistent differences between atenolol and non-atenolol beta-blockers for the primary or secondary outcomes (Supplemental Figure 7).

\section{Discussion}

This umbrella review across cardiovascular indications used meta-analytic data to clarify the evidence basis for beta-blockers in contemporary clinical practice (Table 1, Fig. 5). In patients with coronary disease, there is a trade-off between benefit and risk. Betablockers reduced the risk of incident MI at the expense of higher rates of incident HF, with no effect on mortality. In patients with HFrEF in sinus rhythm, beta-blockers reduced morbidity and mortality, but they had no effect in HFrEF with concomitant atrial fibrillation or those with preserved LVEF. In perioperative patients, although beta-blockers reduced the risk of incident $\mathrm{MI}$ in those undergoing non-cardiac surgery, this was at the expense of increased mortality and stroke. Beta-blockers had no effect on any of the outcomes assessed in patients undergoing cardiac surgery. In hypertension, although beta-blockers had no significant effect compared to placebo or diuretics, they were inferior to RAS antagonists and CCB. These findings highlight the importance of an individualised assessment of indication, comorbidity and understanding of the goal of therapy before routine commencement of beta-blockers. 
Table 1 Evidence map of availability and appraisal of certainty of evidence for beta-blockers across cardiovascular indications

\begin{tabular}{|c|c|c|c|c|}
\hline \multicolumn{2}{|l|}{ Population } & \multirow{2}{*}{$\begin{array}{l}\text { Primary Outcome } \\
\text { All-Cause Mortality }\end{array}$} & \multicolumn{2}{|c|}{ Secondary Outcomes } \\
\hline \multicolumn{2}{|l|}{ Coronary Artery Disease } & & Incident Myocardial Infarction & Incident Heart Failure \\
\hline \multicolumn{2}{|c|}{ Acute coronary syndrome (trials after routine reperfusion) } & $\leftrightarrow$ & $\uparrow$ & $\leftrightarrow$ \\
\hline \multicolumn{2}{|c|}{ Acute coronary syndrome (trials before routine reperfusion) } & $\leftrightarrow$ & $\uparrow$ & $\leftrightarrow$ \\
\hline \multicolumn{2}{|c|}{ Non-acute ischaemic heart disease (trials after routine reperfusion) } & $\downarrow \downarrow \downarrow$ & $\downarrow \downarrow \downarrow$ & $\uparrow$ \\
\hline \multicolumn{2}{|c|}{ Non-acute ischaemic heart disease (trials before routine reperfusion) } & $\uparrow$ & $\uparrow$ & $\leftrightarrow$ \\
\hline \multicolumn{2}{|c|}{ Heart Failure } & All-Cause Mortality & Cardiovascular Mortality & $\begin{array}{c}\text { Heart Failure } \\
\text { Hospitalisation }\end{array}$ \\
\hline \multicolumn{2}{|l|}{ Heart failure with LVEF $<40 \%$, in sinus rhythm } & $\uparrow$ & $\uparrow$ & $\uparrow$ \\
\hline \multicolumn{2}{|l|}{ Heart failure with $\mathrm{LVEF}<40 \%$, in atrial fibrillation } & $\uparrow$ & $\uparrow$ & $\uparrow$ \\
\hline \multicolumn{2}{|l|}{ Heart failure with preserved LVEF } & $\downarrow$ & $\downarrow$ & $\downarrow$ \\
\hline \multicolumn{2}{|l|}{ Perioperative } & All-Cause Mortality & Incident Myocardial Infarction & Incident Stroke \\
\hline \multicolumn{2}{|l|}{ Non-cardiac surgery (high risk of bias trials) } & $\downarrow \downarrow \downarrow$ & $\downarrow \downarrow \downarrow$ & $\downarrow \downarrow \downarrow$ \\
\hline \multicolumn{2}{|l|}{ Non-cardiac surgery (low risk of bias trials) } & $\leftrightarrow$ & $\uparrow$ & $\uparrow \uparrow$ \\
\hline \multicolumn{2}{|l|}{ Cardiac surgery } & $\downarrow$ & $\downarrow$ & $\downarrow$ \\
\hline \multicolumn{2}{|l|}{ Hypertension } & All-Cause Mortality & Incident Myocardial Infarction & Incident Stroke \\
\hline \multicolumn{2}{|l|}{ Beta-blocker vs placebo } & $\leftrightarrow$ & $\leftrightarrow$ & $\downarrow$ \\
\hline \multicolumn{2}{|l|}{ Beta-blocker vs diuretic } & $\leftrightarrow$ & $\downarrow$ & $\downarrow$ \\
\hline \multicolumn{2}{|l|}{ Beta-blocker vs renin angiotensin system antagonist } & $\leftrightarrow$ & $\uparrow$ & $\uparrow$ \\
\hline \multicolumn{2}{|l|}{ Beta-blocker vs calcium channel blocker } & $\leftrightarrow$ & $\uparrow$ & $\uparrow$ \\
\hline Effect of beta-blocker vs control & Bene & & Io Effect & Harm \\
\hline Certainty of Evidence & $\uparrow$ High & $\leftrightarrow$ Moderate & $I_{\text {Low }}$ & $\downarrow \downarrow$ Very Low \\
\hline
\end{tabular}

Certainty of evidence was assessed using the GRADE guidelines. See Supplemental Table 4 for full details. LVEF, left ventricular ejection fraction

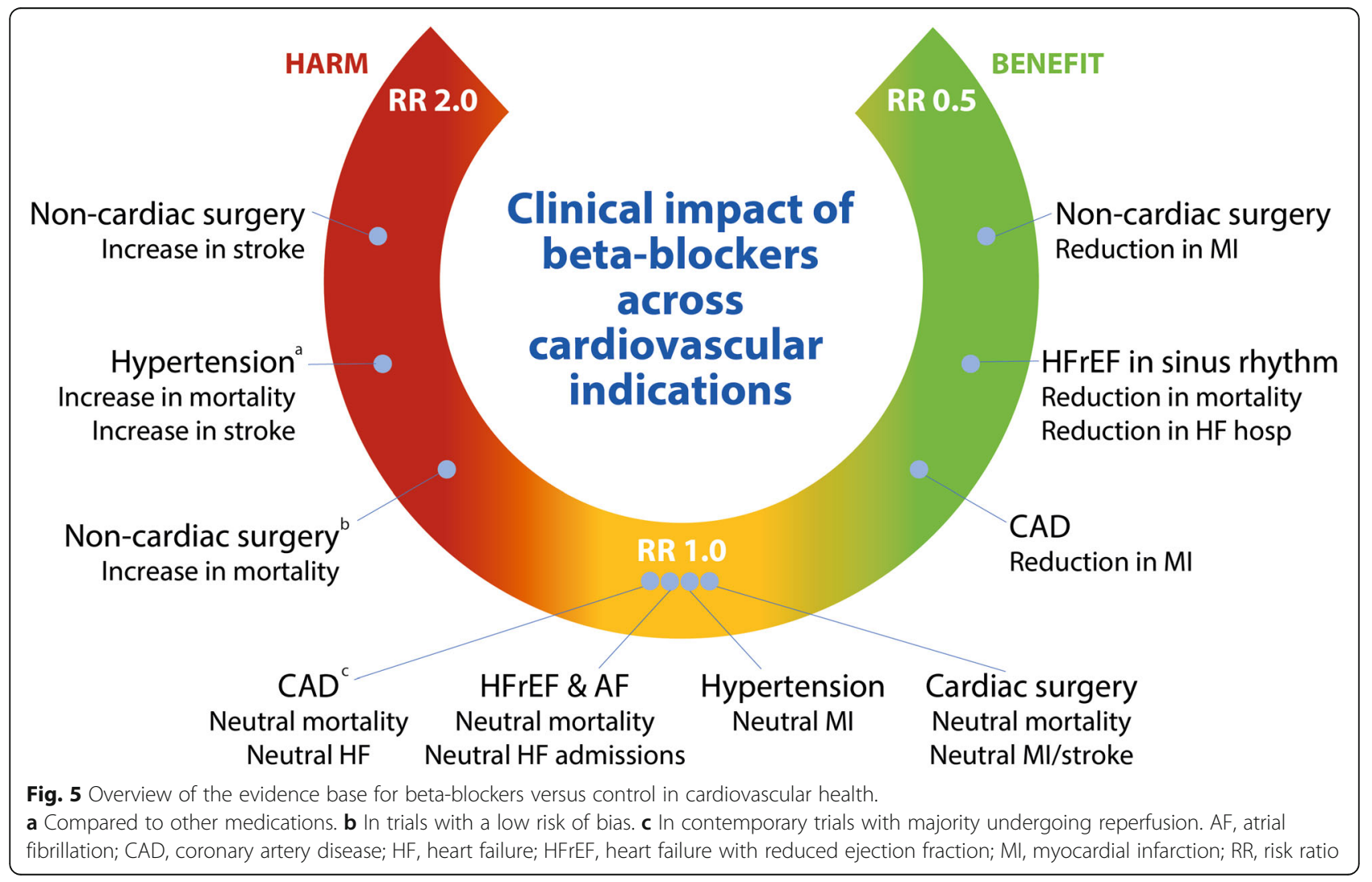




\section{Coronary artery disease}

Although beta-blockers were associated with reduction in mortality in trials before routine reperfusion, the reduction in MI was offset by an increased risk of heart failure. Although MI was a relatively rare event (absolute event rate $\sim 0.01 \%$ ) and heart failure was more common (absolute event rate $\sim 13 \%$ ), the number needed to treat (NNT) to prevent an MI was 118 compared with the number needed to harm $(\mathrm{NNH})$ of 127 to cause an incident heart failure event. Additionally, before routine reperfusion, the event rate for mortality was $7.8 \%$ in control versus $6.7 \%$ with beta-blockers (NNT 89) [6]. There were less tangible benefits in trials with routine reperfusion where the majority of patients received reperfusion with either thrombolytics or coronary intervention. In the International Study of Infarct Survival (ISIS-1) trial in 1986, atenolol significantly reduced vascular death, but only $5 \%$ of patients were on antiplatelet agents [17]. In contrast, in the large Clopidogrel and Metoprolol in Myocardial Infarction Trial (COMMIT) published in 2005, metoprolol failed to reduce mortality where all patients were on aspirin, $50 \%$ on dual antiplatelet agents and $66 \%$ received thrombolysis [18]. The combination of antiplatelet agents with prompt reperfusion therapy in the modern era may restrict the extent of myocardial damage in patients with MI and hence limit the substrate which can benefit from sympathetic inhibition and reduced myocardial oxygen demand.

The balance of benefit versus risk is particularly relevant in acute MI where negative inotropy can lead to cardiogenic shock. This may be more pertinent in larger ST-elevation MI, where early high-dose beta-blockade was associated with increased mortality [18]. In lowerrisk unstable angina patients, beta-blockers reduce the risk of progression to acute MI [19]. Treatment duration may be an important factor to achieve longer-term benefit, but no RCTs directly investigated this issue. The prognostic effects of beta-blockers in chronic stable ischaemic heart disease and stable angina without prior MI remain unanswered. These issues all have important relevance for future guidelines, particularly whether historical data should be used to support contemporary recommendations.

\section{Heart failure}

Beta-blockers have a class I, level of evidence A recommendation in chronic HFrEF, and yet uptake in clinical practice remains suboptimal in certain groups [20, 21]. Subgroup analyses have demonstrated that reduction of mortality and hospitalisation with beta-blockers is consistent in sinus rhythm, regardless of age or gender, baseline heart rate or the degree of reduction in ejection fraction $[1,16,22]$. However, IPD meta-analysis revealed no signal for benefit in the subgroup of patients with atrial fibrillation at baseline [7]. The reasons for this distinction remain unclear, but may relate to differences in the association of heart rate and prognosis compared with sinus rhythm [22], or consequences such as myocardial fibrosis that may influence therapeutic efficacy [23]. Heart failure with intermediate and preserved LVEF accounts for over half of patients, and yet available data is extremely limited [16]. Further RCTs are clearly warranted to address this evidence gap, as well as the interaction with renal dysfunction which is common in patients with HF [24].

\section{Perioperative risk reduction}

Beta-blockers are commonly considered to reduce the risk of cardiovascular events in patients undergoing surgery, but the controversy over integrity of data in the DECREASE studies has led to questions about their true value [25]. In meta-analyses with low risk of bias, we saw an increase in mortality following non-cardiac surgery compared with control and consistent increases in stroke risk. These adverse events offset any benefit from the reduced risk of MI and were consistent with the largest and highest quality individual RCT, the PeriOperative ISchemic Evaluation (POISE) trial [26]. However, the frequency of mortality and incident stroke (absolute event rates $\sim 0.3 \%$ and $\sim 0.6 \%$, respectively) were rarer than myocardial infarction $(\sim 4 \%)$. Indeed, the NNT to prevent an MI was 72 compared with a NNH of 214 to cause a death and 352 to cause a stroke [27]. In cardiac surgery, where one might anticipate a prognostic benefit from beta-blockers, we found no appreciable reduction in events, including for incident MI.

\section{Hypertension}

Beta-blockers are no longer considered as a preferred initial therapy for essential hypertension [9]. The changing approach and therapeutic options are further clarified in the most recent guidelines [10]. However, many patients still receive beta-blockers or continue therapy from historical prescriptions [28]. Our analysis confirms that beta-blockers are inferior to other agents (most notably CCB and RAS antagonists), particularly in preventing strokes. This may be partly explained by differences in achieved BP, including central systolic BP between different drug treatments, to which cerebrovascular events may be particularly sensitive. In addition, betablockers are somewhat less effective than RAS antagonists and CCB in preventing target organ damage.

Importantly, beta-blockers are a heterogeneous class. Whilst vasodilating beta-blockers, such as nebivolol, have demonstrated favourable effects on central BP and cardiovascular surrogates, RCTs with these newer beta-blockers in hypertensive patients are currently lacking. It is possible that there are important differences between beta- 
blockers in efficacy and safety; however, there are insufficient data to be certain as atenolol was utilised in $~ 75 \%$ of trials (our sensitivity analysis could only group together 'non-atenolol' studies). Although there remains a place for beta-blockers in resistant hypertension or those with cardiovascular comorbidities, our data would suggest that physicians should be more aggressive in switching to alternative classes of anti-hypertensive medication.

\section{Strengths and limitations}

The strength of this analysis was the use of a systematic and methodical approach to assess all published metaanalyses of randomised trials across different cardiovascular diseases. By focusing on the highest quality data through a detailed risk of bias and quality assessment, we were able to come to conclusions across various cardiovascular conditions and subgroups. The trial populations were heterogeneous, but this provides results that are more likely to represent clinical practice. It would not have been feasible to assess all individual RCTs due to the vast number included in our analysis. Our analysis provides the most comprehensive and contemporary summary of the efficacy of beta-blockers across cardiovascular diseases, thereby aiding physicians to initiate, maintain or withdraw therapy in a patient group that frequently has multi-morbidity and more than one clinical indication.

As with all systematic reviews, we are limited by the individual RCTs and the methodology of the component meta-analyses. IPD has important advantages over aggregate data meta-analysis, including the ability to improve data quality and increase the precision of effect size. Unfortunately, the series of IPD analyses from the Beta-blockers in Heart Failure Collaborative Group [29] were the only IPD studies available. Nevertheless, at least for major outcomes, conventional meta-analysis can provide similar results and conclusions [30].

There are cardiovascular indications for betablockers where data are extremely limited. Betablockers are commonly used to control heart rate in patients with atrial fibrillation; however, the evidence base is extremely limited at present [31] and we identified no studies eligible for inclusion. Other cardiac populations where beta-blockers are regularly prescribed but where randomised trial evidence is limited include chemotherapy toxicity, cardiomyopathies and other arrhythmias (atrial and ventricular tachycardia).

There are also important and complex pharmacokinetic and pharmacodynamic differences between betablocker subtypes, including lipid solubility, intravenous versus oral administration routes, bioavailability and first-pass metabolism variations. However, with the exception of hypertension, we were unable to assess heterogeneity of treatment effects between different beta- blockers [32]. Finally, the trade-off between efficacy and adverse events will vary according to individual patient characteristics (cardiovascular condition, disease severity and course, comorbidities, and coexisting therapies) and beta-blocker effects (pharmacodynamics, receptor selectivity, dose and route of administration). All of these factors, and more, will impact on the clinical decision to prescribe beta-blocker therapy.

\section{Conclusions}

Although beta-blockers are widely used in routine clinical practice, this analysis indicates that their overall clinical effect depends strongly on the clinical situation. In patients with heart failure and reduced ejection fraction who are in sinus rhythm, beta-blockers show clear benefit in terms of mortality reduction and lower rates of hospitalisation. However, beta-blockers show neutral effects for many other clinical situations in the modern era, and in some cases, harm.

\section{Supplementary information}

Supplementary information accompanies this paper at https://doi.org/10. 1186/s12916-020-01564-3.

\section{Additional file 1.}

\section{Acknowledgements}

We thank Mr. Simon Coates, Enquiries and Clinical Support Librarian, UCL Cruciform Hub, for his expertise and guidance in finalising the search strategy.

\section{Authors' contributions}

OJZ developed the eligibility criteria, performed the primary literature search and contributed to the data extraction and drafting of the manuscript. MS contributed to the literature search, data extraction and drafting of the manuscript. JPH contributed to the data extraction and drafting of the manuscript.

DIB contributed to the data extraction and drafting of the manuscript. DPF contributed to the data extraction and critical revision of the manuscript. FR contributed to data the extraction and critical revision of the manuscript. DK designed the study concept, led the study group and performed the statistical analysis and drafting of the manuscript. The authors read and approved the final manuscript.

\section{Funding}

Dr. Kotecha is funded by a National Institute for Health Research (NIHR) Career Development Fellowship (CDF-2015-08-074) and supported by a British Heart Foundation (BHF) Accelerator Award to the University of Birmingham Institute of Cardiovascular Sciences (AA/18/2/34218). The opinions expressed are those of the authors and do not represent the BHF, the NIHR or the UK Department of Health.

Availability of data and materials

All data generated or analysed during this study are included in this published article [and its supplementary information files].

Ethics approval and consent to participate

Not applicable (based on published data).

Consent for publication

Not applicable. 


\section{Competing interests}

All authors have completed the ICMJE uniform disclosure form and declare the following: OJZ, MS, JPH, DIB and DPF have no relevant conflicts. FR received as direct personal payment speaker fees, honoraria, consultancy, advisory board fees, investigator, committee member from Amgen, Boehringer Ingelheim Novartis, Pfizer, BMS, Servier, Sanofi Aventis, Zoll Medical, St. Jude Medical, Fresenius Nutrition, Vifor International, Cardiorentis and Heartware and as payment to institution speaker fees, honoraria, consultancy, advisory board fees, investigator, committee member from Bayer, Novartis and St. Jude Medical. DK reports grants from Menarini and personal fees from Bayer, Atricure, Myokardia and Amomed, all outside the submitted work, and is the Chief Investigator of the RATE-AF clinical trial (NCT02391337), Steering Group Lead for the Beta-Blockers in Heart Failure Collaborative Group (BB-meta-HF; NCT NCT00832442), and a member of the consortium for an EU/EFPIA Innovative Medicines Initiative on big data for ACS/AF/HF (116074; BigData@Heart).

\section{Author details}

'University of Birmingham Institute of Cardiovascular Sciences, Medical School, Birmingham B15 2TT, UK. ${ }^{2}$ University College London, London WC1E 6BT, UK. Imperial College London, London SW7 2AZ, UK. ${ }^{4}$ Kings College London, London WC2R 2LS, UK. ${ }^{5}$ University Hospital Zurich, 8091 Zürich, Switzerland. ${ }^{6}$ Monash Centre of Cardiovascular Research \& Education in Therapeutics, Monash University, Melbourne, Victoria 3004, Australia. ${ }^{7}$ University Hospitals Birmingham NHS Foundation Trust, Queen Elizabeth Hospital, Institute of Translational Medicine, Birmingham B15 2GW, UK.

\section{Received: 15 November 2019 Accepted: 17 March 2020} Published online: 05 May 2020

\section{References}

1. Kotecha D, Manzano L, Krum H, Rosano G, Holmes J, Altman DG, Collins PD, Packer M, Wikstrand J, Coats AJ, et al. Effect of age and sex on efficacy and tolerability of beta blockers in patients with heart failure with reduced ejection fraction: individual patient data meta-analysis. BMJ. 2016;353:11855.

2. Barron AJ, Zaman N, Cole GD, Wensel R, Okonko DO, Francis DP. Systematic review of genuine versus spurious side-effects of beta-blockers in heart failure using placebo control: recommendations for patient information. Int J Cardiol. 2013;168(4):3572-9.

3. Hjalmarson A, Elmfeldt D, Herlitz J, Holmberg S, Malek I, Nyberg G, Ryden L, Swedberg K, Vedin A, Waagstein F, et al. Effect on mortality of metoprolol in acute myocardial infarction. A double-blind randomised trial. Lancet. 1981;2(8251):823-7.

4. Chen J, Radford MJ, Wang Y, Marciniak TA, Krumholz HM. Effectiveness of beta-blocker therapy after acute myocardial infarction in elderly patients with chronic obstructive pulmonary disease or asthma. J Am Coll Cardiol. 2001;37(7):1950-6.

5. O'Gara PT, Kushner FG, Ascheim DD, Casey DE Jr, Chung MK, de Lemos JA Ettinger SM, Fang JC, Fesmire FM, Franklin BA, et al. 2013 ACCF/AHA guideline for the management of ST-elevation myocardial infarction: executive summary: a report of the American College of Cardiology Foundation/American Heart Association Task Force on Practice Guidelines. Circulation. 2013;127(4):529-55.

6. Bangalore S, Makani H, Radford M, Thakur K, Toklu B, Katz SD, DiNicolantonio JJ, Devereaux PJ, Alexander KP, Wetterslev J, et al. Clinical outcomes with beta-blockers for myocardial infarction: a meta-analysis of randomized trials. Am J Med. 2014;127(10):939-53.

7. Kotecha D, Holmes J, Krum H, Altman DG, Manzano L, Cleland JG, Lip GY, Coats AJ, Andersson B, Kirchhof P, et al. Efficacy of beta blockers in patients with heart failure plus atrial fibrillation: an individual-patient data metaanalysis. Lancet. 2014;384(9961):2235-43.

8. Bouri S, Shun-Shin MJ, Cole GD, Mayet J, Francis DP. Meta-analysis of secure randomised controlled trials of beta-blockade to prevent perioperative death in non-cardiac surgery. Heart. 2014;100(6):456-64.

9. National Institute for Health and Care Excellence: The clinical management of primary hypertension in adults: clinical guideline 127. 2011.

10. Williams B, Mancia G, Spiering W, Agabiti Rosei E, Azizi M, Burnier M, Clement DL, Coca A, de Simone G, Dominiczak A, et al. 2018 ESC/ESH Guidelines for the management of arterial hypertension. Eur Heart J. 2018; 39(33):3021-104
11. Lee DS, Tu JV, Juurlink DN, Alter DA, Ko DT, Austin PC, Chong A, Stukel TA, Levy D, Laupacis A. Risk-treatment mismatch in the pharmacotherapy of heart failure. JAMA. 2005;294(10):1240-7.

12. Soumerai SB, McLaughlin TJ, Spiegelman D, Hertzmark E, Thibault G, Goldman L. Adverse outcomes of underuse of beta-blockers in elderly survivors of acute myocardial infarction. JAMA. 1997;277(2):115-21.

13. Kotecha D, Ziff O. Efficacy of beta-blockers across cardiovascular health: a systematic review of meta-analyses. PROSPERO International prospective register of systematic reviews; 2016. p. CRD42016038375.

14. Moher D, Liberati A, Tetzlaff J, Altman DG, Group P. Preferred reporting items for systematic reviews and meta-analyses: the PRISMA statement. Open Med. 2009;3(3):e123-30.

15. Guyatt GH, Oxman AD, Vist GE, Kunz R, Falck-Ytter Y, Alonso-Coello P, Schunemann HJ. GRADE: an emerging consensus on rating quality of evidence and strength of recommendations. BMJ. 2008;336(7650):924-6.

16. Cleland JGF, Bunting KV, Flather MD, Altman DG, Holmes J, Coats AJS, Manzano L, McMurray JJV, Ruschitzka F, van Veldhuisen DJ, et al. Betablockers for heart failure with reduced, mid-range, and preserved ejection fraction: an individual patient-level analysis of double-blind randomized trials. Eur Heart J. 2018;39(1):26-35.

17. ISIS-1. Randomised trial of intravenous atenolol among 16027 cases of suspected acute myocardial infarction: ISIS-1. First International Study of Infarct Survival Collaborative Group. Lancet. 1986;2(8498):57-66.

18. Chen ZM, Pan HC, Chen YP, Peto R, Collins R, Jiang LX, Xie JX, Liu LS, group Cc. Early intravenous then oral metoprolol in 45,852 patients with acute myocardial infarction: randomised placebo-controlled trial. Lancet. 2005; 366(9497):1622-32.

19. Yusuf S, Peto R, Lewis J, Collins R, Sleight P. Beta blockade during and after myocardial infarction: an overview of the randomized trials. Prog Cardiovasc Dis. 1985;27(5):335-71.

20. Komajda M, Follath F, Swedberg K, Cleland J, Aguilar JC, Cohen-Solal A, Dietz R, Gavazzi A, Van Gilst WH, Hobbs R, et al. The EuroHeart Failure Survey programme--a survey on the quality of care among patients with heart failure in Europe. Part 2: treatment. Eur Heart J. 2003;24(5):464-74.

21. Komajda M, Hanon O, Hochadel M, Lopez-Sendon JL, Follath F, Ponikowski P, Harjola VP, Drexler H, Dickstein K, Tavazzi L, et al. Contemporary management of octogenarians hospitalized for heart failure in Europe: Euro Heart Failure Survey II. Eur Heart J. 2009;30(4):478-86.

22. Kotecha D, Flather MD, Altman DG, Holmes J, Rosano G, Wikstrand J, Packer M, Coats AJS, Manzano L, Bohm M, et al. Heart rate and rhythm and the benefit of beta-blockers in patients with heart failure. J Am Coll Cardiol. 2017;69(24):2885-96.

23. Neilan TG, Shah RV, Abbasi SA, Farhad H, Groarke JD, Dodson JA, CoelhoFilho O, McMullan CJ, Heydari B, Michaud GF, et al. The incidence, pattern, and prognostic value of left ventricular myocardial scar by late gadolinium enhancement in patients with atrial fibrillation. J Am Coll Cardiol. 2013; 62(23):2205-14.

24. Kotecha D, Gill SK, Flather MD, Holmes J, Packer M, Rosano G, Böhm M, McMurray JJV, Wikstrand J, Anker SD, et al. Impact of renal impairment on beta-blocker efficacy in patients with heart failure. J Am Coll Cardiol. 2019; 74(23):2893-904.

25. Koudastal PJ, Lowenberg B, van der Maas PJ, Oosting JM, Peters RJG, Rabelink AJ, Board of Erasmus MC Follow-up Investigation Committee: Report on the 2012 follow-up investigation of possible breaches of academic integrity. 2012

26. Devereaux PJ, Yang H, Yusuf S, Guyatt G, Leslie K, Villar JC, Xavier D, Chrolavicius S, Greenspan L, Pogue J, et al. Effects of extended-release metoprolol succinate in patients undergoing non-cardiac surgery (POISE trial): a randomised controlled trial. Lancet. 2008;371(9627):1839-47.

27. Blessberger H, Kammler J, Domanovits H, Schlager O, Wildner B, Azar D, Schillinger M, Wiesbauer F, Steinwender C. Perioperative beta-blockers for preventing surgery-relatedmortality and morbidity. Cochrane Database of Systematic Reviews. 2014(Issue 9):CD004476. https://doi.org/10.1002/ 14651858.CD004476.pub2.

28. Hwang AY, Dave C, Smith SM. Trends in antihypertensive medication use among US patients with resistant hypertension, 2008 to 2014. Hypertension. 2016;68(6):1349-54.

29. Kotecha D, Manzano L, Altman DG, Krum H, Erdem G, Williams N, Flather MD, Beta-Blockers in Heart Failure Collaborative G. Individual patient data meta-analysis of beta-blockers in heart failure: rationale and design. Syst Rev. 2013;2(7):7. 
30. Tudur Smith C, Marcucci M, Nolan SJ, lorio A, Sudell M, Riley R, Rovers MM, Williamson PR. Individual participant data meta-analyses compared with meta-analyses based on aggregate data. Cochrane Database Syst Rev. 2016; 9:MR000007.

31. Kotecha D, Calvert M, Deeks JJ, Griffith M, Kirchhof P, Lip GY, Mehta S, Slinn G, Stanbury M, Steeds RP, et al. A review of rate control in atrial fibrillation, and the rationale and protocol for the RATE-AF trial. BMJ Open. 2017;7(7): e015099.

32. Opie LH. Effect of beta-adrenergic blockade on biochemical and metabolic response to exercise. Am J Cardiol. 1985;55(10):95D-100D.

\section{Publisher's Note}

Springer Nature remains neutral with regard to jurisdictional claims in published maps and institutional affiliations.

Ready to submit your research? Choose BMC and benefit from:

- fast, convenient online submission

- thorough peer review by experienced researchers in your field

- rapid publication on acceptance

- support for research data, including large and complex data types

- gold Open Access which fosters wider collaboration and increased citations

- maximum visibility for your research: over $100 \mathrm{M}$ website views per year

At BMC, research is always in progress.

Learn more biomedcentral.com/submissions 